infrequency contributes to the difficulty of recognising and avoiding these episodes. The lapse may result from human or mechanical failure, combinations of which came to light in the last episode in Britain, in the Plymouth area. ${ }^{2}$ Rapidly changing technology, particularly during economic stringency, may also cause problems-and the introduction of plastic infusion packs will not necessarily eliminate the risk. A recent report ${ }^{3}$ from the Centre for Disease Control, Atlanta, of an outbreak of infection occurring in the USA in 1970-71, has provided a useful summary of many points which are required knowledge for all concerned with giving intravenous fluids and for microbiologists responsible for investigating reactions thought to have resulted from their use.

The American outbreak, bigger than anything we have experienced in Britain, followed the nationwide use of the contaminated fluid. To investigate the outbreak 25 hospitals were chosen which yielded 378 cases of septicaemia. One fact that emerged was that hospitals with a team including an infection control nurse continually monitoring nosocomial infection were early to spot that an outbreak was in progress. Other institutions (including some large hospitals) where adequate infection control surveillance was not practised became aware that they had been concerned in the outbreak only in retrospect. Nevertheless, the "epidemic" organism was isolated from only six of 1054 random samples of fluid stocks and the overall attack rate was only 1.4 cases per 1000 hospital patients, so that the occult nature of the outbreak was hardly surprising. A few species only of the genus Enterobacter were implicated-a finding in keeping with previous reports, even from Britain. ${ }^{4}$ They included $E$ agglomerans, until recently regarded as a plant pathogen only. All organisms of the Klebsiella-Enterobacter-Serratia group were found to possess a singular ability to multiply in commercial glucose solutions at room temperature, attaining numbers above $10^{8}$ organisms litre within 24 hours. Other organisms, including staphylococci, Proteus, Pseudomonas, and Escherichia coli, either failed to grow or died. 5

Once organisms able to grow in glucose solutions have been introduced into a drip they can persist despite rapid rates of flow of the infusion and even after the bottle has been changed. ${ }^{6} 7$ For this reason Maki et al recommend that the bottle and giving set "down to but not necessarily including the cannula" should be replaced every 24 hours. This advice may be questioned since thrombosis starts in the cannula, which is the favoured site for bacterial colonisation. If routine replacement is to be recommended it must surely include the cannula, but this does not seem justifiable. Conversely, the further recommendation-that, should the cannula need replacing, the entire administration set, including any halfused bottle, should be discarded-is reasonable, as it often applies to long-standing drips, which are particularly prone to infection.

A point favouring the early detection of an outbreak is to identify precisely Gram-negative rods, the organisms concerned being relatively uncommon isolates from ordinary episodes of septicaemia. Some commercially available biochemical sets, particularly those linked to a diagnostic register, may help in this task since they minimise the element of individual guessing in bacteriological identification. When a strain of $E$ agglomerans isolated during the outbreak was subsequently circulated as part of a laboratory quality control programme, $45 \%$ of 250 laboratories taking part failed to identify it correctly. Investigation of these outbreaks should include preservation of all apparatus for examination and culture, noting batch numbers of fluids, withdrawal of sup- plies, and random bacteriological sampling. The method of adding $\times 10$ strength media to whole bottles of fluid is both practicable and sensitive.

It is difficult to advise those responsible for giving intravenous fluids how to detect contaminated batches in practice, and so avoid these episodes. Holding bottles up even to the strongest light will detect only gross contamination-and also tends not actually to be done, especially at night. The most vital point is that the first person to notice any untoward reaction should stop the infusion at the first sign. Once a doctor has been called to confirm this decision (to avoid discontinuing valuable drips which have taken time and skill to put up), the drip should be taken down and the entire apparatus submitted (without contaminating it) for bacteriological culture. In these circumstances antibiotic treatment alone is prone to fail. In the reported outbreak, 17 of 19 patients in whom the administration of the fluid was continued had positive blood cultures 24 hours or more after starting gentamicin therapy.

The most important aspect is to be aware that such outbreaks are possible. With this in view everyone should read this informative report. Overall the episode was thought to have contributed to the deaths of 40 patients. Similar incidents have already occurred in Britain, and undoubtedly they will occur again. When they do, how long will it take for them to be recognised, and how many patients will die in the meantime?

1 Darrell, J H, and Garrod, L P, British Medical fournal, 1969, 2, 481.

2 Meers, P O, et al, Lancet, 1973, 2, 1189.

${ }^{3}$ Maki, D G, et al, American fournal of Medicine, 1976, 60, 471.

${ }^{4}$ Lapage, S P, Johnson, R, and Holmes, B, Lancet, 1973, 2, 284.

${ }^{5}$ Maki, D G, and Martin, W, fournal of Infectious Diseases, 1975, 131, 267.

${ }^{6}$ Maki, D G, Goldmann, D A, and Rhame, F S, Annals of Internal Medicine, 1973, 79, 867.

${ }^{7}$ Michaels, I, and Ruebner, B, Lancet, 1953, 1, 772.

\section{Welded hair}

Shampooing in moderation must be one of the least hazardous things that happens to the hair. But there is a licence for excess in the saying that "cleanliness is next to godliness," whence the aggressively virtuous can derive a rationale for their frequent and vigorous ablutions. Armed with their scallop shell of soap they pursue their hygienic pilgrimage through life, degreasing their scalps at every opportunity and subjecting them to an ordeal by water and hot air. Their activities may be unsuspected until some chance remark, such as, "I wash my hair every day, doctor, and shampoo it once a week." The opposite extreme-total disregard for the person-is more difficult for self-respecting humanity to stomach, but the unshampooed often seem blissfully ignorant of their own state even though they are anaemic from the bloodthirsty appetite of their attendant fauna, which disport themselves in the glades of their host's tangled and filthy locks.

While Agnes Savill ${ }^{1}$ cited ladies whose hair and scalp were kept immaculate with brush and comb only, for most of humanity a weekly shampoo is thought desirable. If harm results from these weekly domiciliary shampoos its victims fail to appear in the clinic. Allergies to the constituents of some shampoos, such as formaldehyde or parabens, have been described $^{2}$ but are rarely seen and are less well known than allergies to other hairdressing materials. Shampoos are more important as primary irritants than as sensitisers, and hence 
they affect hairdressers, who use them repeatedly and often, rather than their clients, whose exposure by comparison is brief and occasional.

A dramatic and distressing result of shampooing with anionic detergents is for the hair to become matted into a bird's nest that no ingenuity can disentangle, for the hairs have become welded together. ${ }^{3}$ The only solution is to cut off the tangle, after which the hair regrows normally. The extreme rarity of this happening compared with the commonplace use of this type of shampoo, makes it difficult to offer any credible explanation, particularly since the same detergent has been used again later with impunity. Hairs can become felted by the physical entanglement of the tile-like scales with which they are covered, as occurs in wigs made of human hair that has been mounted without paying attention to which end of the hair is which. Friction facilitates such felting ${ }^{4}$ and is believed to be the cause of the bird's nests seen in patients who fiddle with and rub their hair obsessively (plica neurotica), but rubbing has not been a particularly prominent feature in the histories of the shampoo cases. Other mechanisms suggested have been electrostatic attraction and viscous fluid weldingthe welding effect is apparent under the scanning electron microscope-but there is no real explanation of the precise circumstances concerned. Perhaps the biggest clue is that the central area of the scalp is worst affected and that peripheral parts may be normal. It is tempting to speculate that conditions are favourable when an undiluted solution of anionic detergent is brought into contact with hair that is either dry or scarcely wet. This is no more than conjecture, though it may be significant that all the patients seem to have been doing their own shampooing.

1 Savill, A, and Warren, C, The Hair and Scalp, 5th edn. London, Arnold, 1962.

${ }^{2}$ Fisher, A A, Contact Dermatitis, 2nd edn. Philadelphia, Lea and Febiger, 1973.

${ }^{3}$ Dawber, R P R, and Calnan, C D, Clinical and Experimental Dermatology, 1976, 1, 155.

4 Bogaty, H, and Dunlap, F E, Archives of Dermatology, 1970, 101, 348.

\section{Mental health reforms}

The Mental Health Act 1959 was in all probability the most important instrument of English legislation yet devised in its effects on the mentally disordered. Yet there were imperfections in its conception-imperfections which have become increasingly apparent in the last 17 years. No matter what, it is likely that the Act would have had to be revised. Nevertheless, an element of urgency was introduced by the tragic failures in the existing procedures in the cases of two men who committed murders of a particularly spectacular and gruesome kind while on conditional discharge from Broadmoor special hospital.

Last month the DHSS published a consultative document, ${ }^{1}$ the work of a committee made up of various government departments whose task it was to consider what amendments should be made to the Act. The committee had been given the benefit of suggestions from professional bodies and individuals: a review submitted by the Royal College of Psychiatrists ${ }^{2}$; the results of the lengthy deliberations of a specially appointed working party; the report ${ }^{3}$ of the Butler Committee (which was concerned with all legislation appertaining to the mentally abnormal offenders including part $\mathrm{V}$ of the Act); and the findings of a one-man inquiry by an American lawyer published under the aegis of MIND. ${ }^{4}$

The term "mental disorder" was introduced in the 1959 Act to cover all forms of mental illness or disability of mind. Of the four statutory sub-categories, the one that has come in for major criticism is "psychopathic disorder." The Butler Committee admitted in its report that to recommend the deletion of the term was outside its remit, but it gave cogent reasons why this should be done, of which by far the weightiest was the continuing uncertainty whether the condition is treatable in a medical sense. Practising psychiatrists would in the main agree; and very few would weep if, despite the legal difficulties, behaviour disorders in general were to be no longer a primary medical responsibility. In this context, the Butler Committee put forward proposals for the training and treatment of dangerous antisocial psychopaths on a voluntary basis in special units, but within the penal system. The Royal College in turn suggested a new definition and classification of "mental disorder," but omitted any reference to psychopathy. It pointed out, however, that if necessary such individuals requiring to be detained and treated under civil orders could be dealt with under "any other disorder or disability of mind," an integral part of the suggested definition. This would have particular relevance when, or (perhaps more pertinently) if, the new regional secure units come into being.

One of the underlying principles on which the 1959 Act was based was that as much treatment as possible, both inpatient and outpatient, should be on an informal (voluntary) basis. Indeed, this policy has been successful : about $90 \%$ of all admissions to hospital and virtually all outpatients are on an informal basis. But there remain, and will always remain, that minority for whom compulsion is necessary. The Royal College is satisfied with the present provisions of part IV of the 1959 Act. MIND, however, would narrow the criteria for compulsory admission to relate more closely to dangerousness to self or others or to grave disablement. The committee maintains, very sensibly, that criteria of this sort would be disadvantageous to those persons suffering from dementia-for example, who are too confused to be able to state or realise their needs. On the other hand, it thought that MIND's narrower criteria might be applied when the time came for the renewal of a compulsory order.

Some sharp criticism of the shorter compulsory orders (sections 25, 29, and 136) was made by MIND; but this view was not shared by either the Royal College or the committee, which has opted for their retention. It must be emphasised that just because these short orders-and in particular section 29 (admission for observation in emergency) and in the Metropolitan area section 136 (place of safety) - are frequently used it does not necessarily mean that they are being abused. The possible alternative to these emergency measures is a 24-hour crisis-intervention service, but the committee points to the inescapable fact that neither the skilled manpower nor the resources are available.

The second part of the consultative document considers the protection of the patient, the staff, and the public. An innovation in the 1959 Act, and perhaps its most important protection against the abuse of compulsory powers, were the mental health review tribunals (MHRTs). In practice, the present powers of MHRTs are "all or nothing," which may explain how conditionally discharged patients succeeded in committing serious offences. To lessen this danger, the committee acknowledges the need for the powers of the MHRT to be extended so as to allow discharges to be delayed until suitable after-care arrangements are made-in effect the opinion held by the 